\title{
El post-conflicto y los desafíos de la protesta social en Colombia
}

\author{
0 pós-conflito e os \\ desafios do protesto social \\ na Colômbia
}

\section{Edwin Cruz Rodríguez ${ }^{1}$}

ecruzr@unal.edu.co

Universidad Nacional de Colombia

Bogotá - Colombia

Artículo recibido: 30/04/15

Artículo aprobado: 28/07/15

Para citar este artículo: Cruz, E. (2015).

El post-conflicto y los desafíos de la protesta social en Colombia.

Ciudad Paz-Ando, 8(1), 84-103

DOI: http://dx.doi.org/10.14483/udistrital.jour. cpaz.2015.1.a05

1 Candidato a Doctor en estudios políticos de la Universidad Nacional de Colombia.

\section{Resumen}

Este artículo analiza los desafíos de la protesta social en un eventual post-conflicto en Colombia. En un escenario de post-conflicto, que propenda por la consolidación de la democracia y la exclusión de la violencia como vía legítima para hacer política, es necesario acabar con el legado contrainsurgente de la Guerra Fría, promover una cultura política que asuma la protesta como el ejercicio legítimo de un derecho y no como una amenaza interna, desprivatizar la función policial y acabar con el paramilitarismo en todas sus formas, desmilitarizar la policía y acoplar los marcos jurídicos a las necesidades razonables del derecho a la protesta.

Palabras clave: post-conflicto, protesta social, contrainsurgencia, Colombia, democracia. 


\begin{abstract}
This paper discusses the challenges of social protest in case of a possible post-conflict in Colombia. In a post-conflict scenario, which aims for the consolidation of democracy and the exclusion of violence as a legitimate way to make politics, it is necessary to put an end to the counterinsurgency legacy of the Cold War, promote a political culture that assumes the protest as a legitimate exercise of a right and not as an internal threat, de-privatize policing and end paramilitarism in all its forms, demilitarize the police and connect the legal framework to the reasonable needs of the right to protest.
\end{abstract}

Key words: post-conflict, social protest, counterinsurgency, Colombia, democracy.

\section{Introducción}

E n los últimos años, la agenda pública en Colombia experimentó una significativa transformación. En efecto, desde el primer gobierno de Juan Manuel Santos (2010-2014), el predominio de la "seguridad democrática" y la "amenaza terrorista" (López de la Roche, 2014) cedió terreno, entre otros, a dos asuntos que han acaparado la atención: las negociaciones de paz con las Fuerzas Armadas Revolucionarias de Colombia (FARC), que se iniciaron a finales de 2012 en La Habana, Cuba, y el auge de la protesta social. De acuerdo con cifras

\section{Resumo}

Este artigo analisa os desafios do protesto social num eventual pós-conflito na Colômbia. Em um cenário de pós-conflito, que procure a consolidação da democracia e da exclusão da violência, como forma legítima de fazer política, é necessário acabar o legado contra-insurgente da Guerra Fria, promover uma cultura política que assuma o protesto como o exercício legítimo dum direito e não como uma ameaça interna, desprivatizar a função policial e acabar com o paramilitarismo, desmilitarizar a polícia e adaptar os marcos jurídicos às necessidades razoáveis do direito ao protesto.

Palavras-chave: pós-conflito, protesto social, contra-insurgência, Colômbia, democracia. del Centro de Investigación y Educación Popular (CINEP), entidad que ha desarrollado una base de datos de luchas sociales cuyos registros se remontan hasta 1975, 2013 fue el año de mayor protesta en las últimas tres décadas con 2027 episodios. El aumento de la protesta y la recomposición de los movimientos sociales se hacen palpables además al observar movilizaciones de gran magnitud, como la del movimiento estudiantil en 2011, el paro cafetero a principios de 2013 y los paros nacionales agrarios de 2013 y 2014 (Cruz, 2012a, 2013, 2014). 
Ambos procesos, las negociaciones de paz y el apogeo de la protesta, no pueden comprenderse de manera aislada, puesto que el primero ha impreso una dinámica particular al sistema político colombiano que ha transformado las condiciones en que se desarrolla la protesta y abierto oportunidades para la acción colectiva. Así por ejemplo, el cambio de estilo en el gobierno Santos, la retórica reformista y las políticas de diálogo, que contrastan con la intransigencia del período de Uribe (2002-2010) frente a ciertos temas, no sólo fomentan una ampliación de expectativas que puede cristalizar en acción colectiva, sino también alteran las correlaciones de fuerza, las coaliciones entre distintos actores y sus repertorios de acción (Wills \& Benito, 2012).

Todo esto plantea grandes interrogantes de cara a un hipotético acuerdo de paz. En teoría, un eventual escenario de post-conflicto ampliaría las oportunidades políticas para la protesta y otros repertorios de acción colectiva. No obstante, no es posible prever si en tal situación se mantendrían los ritmos y niveles de protesta de los últimos años, entre otras cosas porque, como ha demostrado Archila (2003), ésta no ha obedecido a ciclos. Además, los actores sociales pueden optar por distintos repertorios en función del alcance de los posibles acuerdos; por ejemplo, si se amplía la participación electoral es probable que muchos de los actores que han apostado por la protesta pasen a participar en la política institucional, tal como sucedió a principios de los noventa cuando se aprobó la actual Constitución Política (Novoa, 2009). En el peor escenario, podría retornar la "guerra sucia", como sucedió en los años ochenta (Uprimny \& Vargas, 1990), limitando las posibilidades de la protesta.

En cualquier caso, el objetivo de un acuerdo de paz es terminar con la supresión de la política por la violencia que ha caracterizado la historia del país (Sánchez, 1991), lo que debe traducirse en una ampliación del escenario público político hacia la diversidad de proyectos, actores y repertorios de acción que coexisten en la sociedad colombiana. Por tanto, el contexto en que se desarrolla la protesta, la cultura política y los arreglos institucionales que tienen como fin regularla, deben ser repensados en tal escenario.

Este artículo realiza un análisis de los desafíos que enfrentaría la protesta en un eventual post-conflicto. El planteamiento central se resume en que si bien el conflicto armado afecta de distintas formas la protesta, es claro que ha limitado las posibilidades de su desarrollo, principalmente por efecto del legado de la Guerra Fría y la orientación contrainsurgente que asume la protesta como una amenaza articulada a la insurgencia armada y responde con criminalización y represión, tanto oficial como para-oficial. Por consiguiente, en un escenario de post-conflicto, que propenda por la consolidación de la democracia y la exclusión de la violencia como vía legítima para hacer política, es necesario acabar con dicho legado, lo que se traduce en promover una cultura política alejada de la mentalidad contrainsurgente que asuma la protesta como el ejercicio legítimo de un derecho y no como una amenaza, desprivatizar la función policial y acabar con el paramilitarismo en todas sus formas, desmilitarizar la policía y acoplar los marcos jurídicos a las necesidades razonables del derecho a la protesta.

Para desarrollar este argumento, en primer lugar, se examinan las consecuencias del conflicto armado sobre la protesta. Seguidamente, se analiza el legado de las doctrinas contrainsurgentes sobre la sociedad colombiana. En tercer lugar, se estudian las formas de represión oficial y para-oficial que han pre- 
dominado. Finalmente, se analizan los mecanismos institucionales para el manejo de la protesta, la policía y el marco legal.

\section{La violencia y la acción colectiva}

El conflicto armado no implica la desaparición de la protesta social, pues en muchos casos las consecuencias que la violencia produce sobre las comunidades funcionan como desencadenantes de la misma. No obstante, la guerra restringe las posibilidades de articulación de los actores sociales, condición necesaria para generar protestas de amplio alcance como las que en períodos recientes se han producido en otros países de América Latina. Así, en una perspectiva comparativa la guerra ha debilitado tanto los movimientos sociales como la protesta en el país.

¿Cómo afecta el conflicto armado a la protesta social? La protesta social es un repertorio particular de acción colectiva. Se trata de esfuerzos públicos y sostenidos para trasladar a las autoridades las reivindicaciones colectivas (Tilly \& Wood, 2010). Aunque frecuentemente está vinculada con movimientos sociales, se trata de fenómenos distintos. Mientras las protestas pueden revestir un carácter coyuntural con cierto grado de espontaneidad, los movimientos tienen un mayor nivel de organización y permanencia, y pueden optar por otros repertorios de acción (Godás, 2007). No obstante, en la práctica es difícil distinguir con claridad ambos fenómenos y su relación con las dinámicas del conflicto armado.

Tanto la protesta como los movimientos requieren redes de relaciones sociales y organizaciones que les sirvan de base (Melucci, 1999). Por consiguiente, cuando el conflicto armado fractura el tejido social afecta la posibilidad de que surjan protestas y movimientos sociales. La acción colectiva también demanda el desarrollo de organizaciones especializadas, identidades y esquemas compartidos de interpretación del mundo o marcos de acción colectiva (Ruch, 1999; Rivas, 1998), difíciles de desarrollar en condiciones de polarización extrema, restricciones a los derechos de asociación, libertad de expresión y de movimiento que implica la guerra. En fin, el conflicto armado restringe sobremanera las oportunidades políticas para la acción colectiva contestataria al reducir las posibilidades de coalición (Tarrow, 1997).

Todo eso no significa que en medio de la guerra desaparezca por completo la protesta; pero sí complejiza el grado en que las dinámicas de la guerra afectan las variables que la hacen posible. En el caso colombiano existen evidencias de distintos tipos de acción colectiva en medio del conflicto. Por una parte, se desarrolló un vigoroso movimiento por la paz y distintas expresiones organizadas de víctimas (García, 2006). Por otra, sabemos que en los distintos contextos de alto riesgo por la violencia, las poblaciones han ideado formas de actuar colectivamente, aunque no siempre recurran al repertorio de acción arquetípico de la protesta (Peñaranda et. al., 2011). Sin embargo, existe una gran dificultad para la comprensión de las relaciones entre las dinámicas del conflicto armado y las de la movilización social.

En primer lugar, resulta complicado generar baremos agregados para el conflicto armado que permitan realizar explicaciones estadísticas o correlaciones sobre la forma como éste afecta la protesta. Los indicadores convencionales, como la tasa de homicidios, los enfrentamientos, o incluso el dominio sobre territorios de determinados actores armados no dan cuenta del conflicto y de las variables que involucra en toda su complejidad y, aún si así fuera, pueden tener repercusiones 
distintas sobre la protesta, facilitarla, provocarla o inhibirla. Además, la cuantificación de las protestas no es suficiente para comprender su relación con las lógicas del conflicto, puesto que las protestas y otras formas de acción colectiva pueden tener distintos sentidos, diversas demandas y múltiples blancos $u$ adversarios.

A este respecto, Peñaranda et. al. (2011) presentan una rica aproximación cualitativa y cuantitativa que además se destaca por la variedad de casos regionales que estudian. De esta investigación se puede colegir que la protesta social se presenta tanto en las regiones en las que existe un dominio consolidado por parte de un actor armado, como en aquellas en las que su dominación se ve amenazada y en las que existe una confrontación sin una dominación territorial y poblacional clara. En otras palabras, no existe una correlación entre el comportamiento de las principales variables del conflicto armado y el de la protesta. Los actores sociales establecen diversos tipos de relación con los actores armados, de tal manera que en los territorios donde existe un claro dominio y un bajo nivel de violencia, aún pueden presentarse protestas en contra de políticas determinadas del actor dominante. En el mismo sentido, un mayor nivel de riesgo para la protesta no anula la posibilidad de que esta se produzca, pues de hecho en ocasiones el recrudecimiento de la violencia desencadena la resistencia colectiva de las poblaciones.

Existen estudios de caso que informan sobre el comportamiento diverso de los actores sociales en contextos de alto riesgo. Salazar y Castillo (2001) se esforzaron por aplicar la teoría de juegos para develar los cursos de acción que los actores armados y civiles podrían adoptar en distintas situaciones del conflicto. Un hallazgo de interés en este sentido es que tipo de acción colectiva; por el contrario, los designios estratégicos empiezan por responder cuándo es posible y deseable actuar colectivamente. Así mismo, no siempre se opta por repertorios contestatarios; en muchos casos la acción colectiva toma la forma de desplazamientos masivos o evasión, por ejemplo. En todo caso, la acción colectiva y su repertorio dependerán de los lazos comunitarios, las redes sociales o el capital social y cultural con que cuenten las poblaciones; incluso, donde se presentan mayores niveles de organización social los actores armados encuentran más dificultades para establecerse (Pécaut, 2001). De ahí que, por ejemplo, las comunidades indígenas del Cauca presenten un nivel importante de resistencia frente a todos los actores de la guerra (Peñaranda, 2006).

No obstante, como antes se afirmaba, la protesta puede tener diversos sentidos en medio del conflicto. Así por ejemplo, existen poblaciones que han desarrollado formas organizativas y acciones colectivas reivindicando la paz o sustrayéndose a las dinámicas del conflicto armado, como ocurre en la región del Magdalena Medio o en Urabá con la Comunidad de Paz de San José de Apartadó (Silva, 2011; Uribe De Hincapié, 2004). De la misma manera, las poblaciones pueden ser obligadas a participar en movilizaciones, como ocurrió en 2000 y 2001, cuando los grupos paramilitares obligaron a los pobladores de municipios vecinos de Antioquia y Bolívar a rechazar una zona de encuentro para llevar a cabo la "Convención Nacional", propuesta en ese entonces en el marco de los diálogos de paz con el ELN (Gutiérrez, 2004). Más aún, muchas veces los actores sociales han quedado en medio del fuego cruzado de actores ilegales cuyo enfrentamiento es inesperado, como ocurrió con los sindicalistas bananeros y las disputas entre las FARC y los 


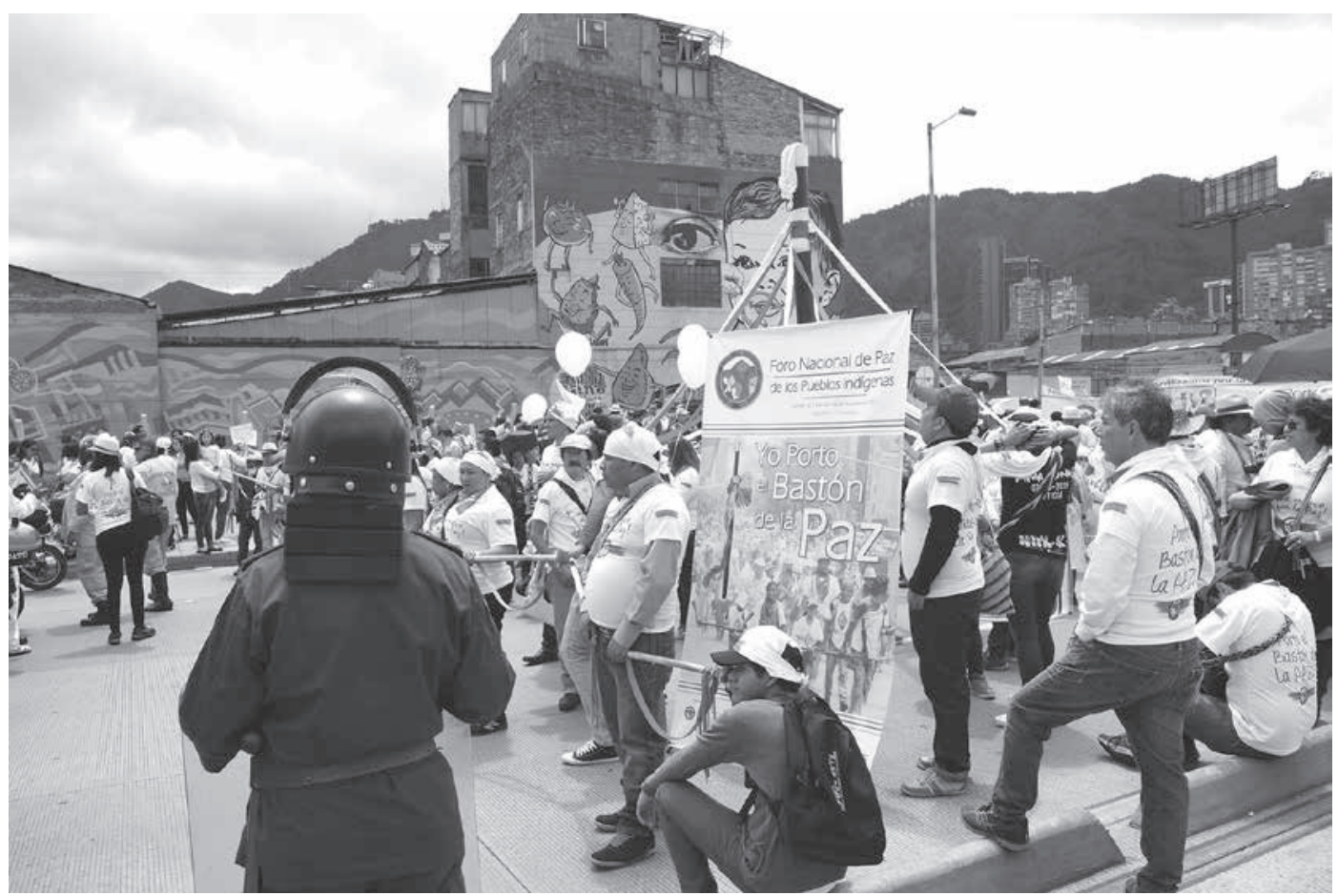

(C) IPAZUD

desmovilizados del Ejército Popular de Liberación en la región de Urabá (Romero, 2003).

Finalmente, las formas en que la guerra afecta la protesta social no solamente se complejizan por la diversidad de situaciones regionales, sino también en función del poder de los actores sociales organizados. Así permiten inferirlo las recientes investigaciones sobre la victimización en el caso del sindicalismo, puesto que han sido los sindicatos con más arraigo, como los de la educación o del petróleo, y aquellos con un claro ideario de izquierda como la Central Unitaria de Trabajadores (CUT), los que han resultado invariablemente atacados, en particular por el paramilitarismo (Valencia \& Celis, 2012; Archila et. al., 2012).

Así pues, la relación entre conflicto armado y protesta no puede reducirse a una relación lineal entre variables. Dicha relación varía de una región a otra, en función del nivel de organización de las comunidades, la cultura po- lítica y el desarrollo de identidades colectivas, los intereses económicos que convergen sobre los territorios, las tradiciones de lucha y las relaciones que los actores sociales establecen con los armados, entre otros. Sin embargo, la guerra limita las posibilidades de desarrollar movilizaciones de largo aliento y amplio alcance territorial. Como antes se mencionó, la protesta requiere la construcción de redes de relaciones sociales, procesos organizativos, marcos de acción colectiva o plataformas discursivas, muy difíciles de desarrollar en un contexto de guerra. Por esa razón, la protesta muchas veces queda confinada a la resistencia y a la violencia, sin posibilidades de trascender hacia proyectos de mediano y largo plazo. A la espera de estudios que permitan corroborar esta hipótesis, por ahora es posible una aproximación comparativa.

La historia contemporánea de Colombia contrasta con la tendencia latinoamericana 
por la ausencia de grandes movilizaciones sociales. La crisis argentina en 2001 simboliza la apertura de un inédito ciclo de movilizaciones en la región. En enero de 2000, el movimiento indígena ecuatoriano había encabezado, junto con sectores del ejército, una insurrección (Ramírez, 2000); en abril del mismo año, tuvo lugar la "guerra del agua" -las protestas en contra de la privatización del servicio del agua- en Cochabamba Bolivia (Kruse, 2005); bajo la consigna de "nada solo para los indios", en febrero de 2001 tuvo lugar otro "levantamiento indígena" en Ecuador, esta vez en protesta por el incremento en el precio de los combustibles y bienes de primera necesidad (Lucas \& Cucurella, 2001); también en junio y julio de 2001 ocurrió un "cerco" de la ciudad de La Paz, propiciado por el incumplimiento de los acuerdos entre el gobierno y los movimientos sociales, y en la vecina ciudad de El Alto, incluso se llegó a proclamar la autodeterminación de las naciones originarias aymara-quechua y a expulsar las autoridades del Estado boliviano. En los años siguientes las protestas ascendieron de tal forma que en septiembre de 2003, la movilización en contra de la exportación del gas boliviano por un puerto Chileno, conocida como "guerra del gas", terminó con la caída del gobierno de Gonzalo Sánchez de Lozada (Cabezas, 2007). De forma similar, en abril de 2005 la "rebelión de los forajidos" daba al traste con el gobierno de Lucio Gutiérrez en Ecuador (Acosta, 2005).

La particularidad colombiana no sólo es contemporánea, sino una característica propia de su historia política. Así por ejemplo, aquí los partidos tradicionales (Liberal y Conservador) subsistieron desde el siglo XIX y, a diferencia de casos como México, Argentina o Brasil, no fueron reemplazados por partidos populistas (Pécaut, 2001). Así mismo, el régimen democrático se ha caracterizado por su estabilidad y persistencia pese a los altos niveles de violencia, que contrasta con el auge de los regímenes autoritarios en la segunda mitad del siglo XX, muchos de los cuales registraron niveles de represión más bajos (Gutiérrez, 2014). Sin embargo, el país comparte con la región variables que están en la raíz del mencionado ciclo de protesta, como el descontento frente a los programas de ajuste estructural y al extractivismo, la emergencia de expresiones organizativas alternativas a la clase obrera como los movimientos étnicos, etarios y de mujeres, el repunte de la izquierda en el campo electoral (Rodríguez et. al., 2005) -particularmente en el control de la capital- e, incluso, el declive de los partidos tradicionales (Gutiérrez, 2007). Todo esto permite inferir que una perspectiva comparativa tendría por fuerza que resaltar lo que constituye tal vez la única variable excepcional del caso colombiano: la existencia del conflicto armado, a la hora de explicar la "debilidad" de la protesta y los movimientos sociales (Archila, 2002).

En suma, las dinámicas del conflicto no inhiben la protesta social y, aunque las formas en que la afectan varían de acuerdo a diversos factores, sí terminan por limitar sus alcances. Esto puede apreciarse al constatar la ausencia de grandes movilizaciones y fuertes movimientos sociales en el país, pese a compartir varias de las características que en otros países han coadyuvado a producirlos. Pero no sólo las dinámicas concretas de la violencia restringen las posibilidades de la acción colectiva, puesto que la guerra hace que las doctrinas y políticas de contrainsurgencia permeen otras dimensiones de la vida social y generen un contexto de criminalización y represión de la protesta, como se muestra a continuación. 


\section{De la sociedad contrainsurgente a la gobernabilidad democrática}

Si bien tiene profundas raíces en la historia, el conflicto armado colombiano es una prolongación local de la Guerra Fría. Tanto la Doctrina de Seguridad Nacional (DSN) como las políticas contrainsurgentes desbordaron los marcos de la seguridad y la fuerza pública y se enraizaron en diversos contextos y prácticas sociales, dando lugar a una suerte de "sociedad contrainsurgente" orientada a la eliminación de la amenaza interna. Como consecuencia, la protesta ha sido sistemáticamente criminalizada y reprimida al concebirse como parte de un proyecto insurgente.

En efecto, debido inicialmente al encuadre del conflicto armado en el marco de la Guerra Fría y a su intensificación en los primeros lustros del siglo XXI de la mano de la lucha contra el terrorismo, en Colombia aún predomina lo que Franco (2002) denominó la "sociedad contrainsurgente". Sus orígenes se remontan a la influencia que en la política militar y en la política de seguridad tuvo la DSN que, como es bien sabido, tuvo distintos desarrollos en América Latina luego de la Revolución Cubana, aunque en Colombia influyó con mayor ahínco la orientación norteamericana, y en varios casos condujo a la instauración de regímenes autoritarios (Leal, 2006). Uno de los postulados básicos de tal perspectiva radicaba en una cierta división del trabajo según la cual mientras EEUU enfrentaba el socialismo internacional, los demás países debían hacer frente al "enemigo interno".

Esto, aunado a la emergencia de la subversión armada, generó un desborde de la mentalidad y las prácticas contrainsurgentes más allá de las fronteras del campo militar hasta configurar, virtualmente, una "sociedad contrainsurgente", esto es, una sociedad cuyo fin principal es salvaguardar el orden social vigente, de la permanente y omnipresente amenaza interna. De esa forma, y siguiendo a Franco (2002), se configura un "complejo contrainsurgente" que articula tanto los intereses de los organismos estatales como de las élites políticas y económicas en torno a la salvaguarda del orden. Esto se traduce en la militarización de la sociedad, entendida como la proliferación de organismos armados legales e ilegales, públicos y privados, y de la ideología del militarismo, así como en el auge de la propaganda contrainsurgente, que busca articular la población a la lucha contrainsurgente por distintas vías, desde los medios de comunicación hasta su vinculación con formas determinadas de control social, entre otros.

Respecto de la protesta social, la configuración de una sociedad contrainsurgente tiene tres consecuencias básicas. En primer lugar, la instauración de un cierto grado de excepcionalidad jurídica de facto que se explica porque:

El complejo contrainsurgente, como puede inferirse de la Doctrina de Seguridad Nacional y del desarrollo de diversas experiencias históricas, requiere del recurso a un poder arbitrario, por fuera de los constreñimientos del orden jurídico nacional e internacional, para garantizar la integridad del poder estatal. Ello responde a un razonamiento lógico en el ámbito militar según el cual un ejército irregular difícilmente se puede combatir a partir de las estrategias convencionales a las cuales se restringe el accionar de las fuerzas armadas oficiales de un Estado. (Franco, 2002, p. 60)

En segundo lugar, esa excepcionalidad se traduce en el poder de ciertos organismos para determinar qué tipo de prácticas y sujetos pueden constituir una amenaza al orden 
social. En otras palabras, si bien la contrainsurgencia tiene como razón de ser la existencia de un proceso insurgente armado, un proyecto alternativo de orden social que busca imponerse por la fuerza, la amenaza se disemina más allá de ese enemigo y resulta prácticamente imposible generar criterios fiables para determinarla. De esta manera, las amenazas terminan siendo definidas tanto en virtud de criterios políticos como en función de intereses económicos particulares e incluso de otro tipo de intereses personales, y no necesariamente por las instituciones habilitadas constitucionalmente para esa función. En el fondo, potencialmente todos los sujetos sociales son una amenaza. Eso conduce a un tratamiento desproporcionado de formas de acción política como la protesta que, por la demanda de transformación que plantea al orden social, termina asimilándose a una parte de la insurgencia, en lugar de reconocerse como un derecho legítimo de la ciudadanía, lo que hace que reciba fundamentalmente un tratamiento militar y represivo.

Por esa razón, y en tercer lugar, la contrainsurgencia se traduce en la asociación de la protesta social con el desorden y la ingobernabilidad. Esa sinonimia no sólo está presente en el discurso de las autoridades públicas, sino también en el de los medios de comunicación, que adoptan un lenguaje castrense para referirse a la protesta (disturbios, desórdenes, vandalismo, revueltas, tumultos, motines, etc.). Así, la protesta social no se concibe como un derecho ciudadano, sino que, en el mejor de los casos, se asimila a un crimen. Es lo que en el contexto colombiano se conoce como la criminalización de la protesta, que aunada al carácter difuso de la amenaza contrainsurgente que antes se mencionó, conlleva a la práctica recurrente de deslegiti- mar cualquier manifestación de descontento al ligarla a una expresión de la subversión armada. Esto constituye uno de los argumentos que frecuentemente aducen las autoridades civiles y militares a fin de justificar procedimientos represivos.

Como es bien sabido, estos tres elementos tomaron ahínco en el contexto post 11 de septiembre, que coincidió con la implementación de la política de seguridad democrática. En efecto, durante la Guerra Fría el tema predominante en la agenda de seguridad en los países de América Latina fue el de la seguridad nacional, articulado a los intereses de EEUU. El fin de la Guerra Fría significó una transición en las concepciones de seguridad caracterizada por la definición de amenazas más difusas, el desplazamiento de la primacía de lo militar, la aparición de actores no estatales en el plano de la seguridad, la creciente interdependencia y la conciencia sobre la existencia de problemas que no los puede resolver un solo Estado; a ello se le denominó "nueva agenda" (Hirts, 2003).

A partir de lo que el entonces Secretario de Estado norteamericano, Colin Powell, denominó como "post 11 de septiembre", se asistió a una re-definición drástica de la agenda en la que la lucha contra el terrorismo fue la principal prioridad. Este planteamiento coincidió con el interés del gobierno Uribe por desarrollar su política de seguridad democrática, de tal manera que ya no se reconoció la existencia de un conflicto armado, sino que se ubicó la situación en el marco del terrorismo: en Colombia había una "amenaza terrorista". Por eso, la principal preocupación de Uribe en la política internacional fue incorporar a Colombia en la guerra contra el terrorismo, a partir del 9/11 con el fin de obtener el apoyo de EEUU, que por su parte ya había interve- 
nido abiertamente en el conflicto armado por vía del Plan Colombia (Pécaut, 2003). En el interior del país esto se tradujo en una agudización de la guerra en ciertas regiones y, en términos generales, en la estigmatización de los movimientos sociales y de los críticos del gobierno en todas las orillas políticas.

Por todo lo anterior, un desafío para el post-conflicto se resume en que la sociedad colombiana debe dejar de ser una sociedad contrainsurgente, superar de una vez el legado de la Guerra Fría a fin de posibilitar el ejercicio del derecho a disentir como condición para la convivencia y el pluralismo político (Cárdenas, 2003). Esto supone distintas transformaciones en varios niveles, en las instituciones públicas y privadas pero también en la cultura política, de tal forma que la protesta pueda ser concebida como un derecho legítimo y no como una amenaza o un crimen. Más aún, tales transformaciones empiezan por entender que la protesta social es necesaria para la consolidación del régimen político democrático y para la gobernabilidad. La protesta y los movimientos sociales permiten la expresión política de actores sociales sub-representados o excluidos de la esfera pública-política, contribuyen a la socialización de la ciudadanía en los valores de la democracia, enriquecen el debate político, visibilizan problemas socialmente relevantes, coadyuvan en la formación de una sociedad civil fuerte, diversifican la cultura política y fomentan el control social de la gestión pública (Cruz, 2012b). De esa forma, la protesta social es fundamental para el mejoramiento de la gobernabilidad democrática, en la medida en que contribuyen a la inclusión de demandas y actores diversos al sistema político que muchas veces no son canalizados por los partidos políticos y, por tanto, a la legitimidad y la eficacia del mismo (Revilla, 1994; Torres, 1993).

\section{La represión oficial y para-oficial}

La DSN y las políticas de contrainsurgencia se traducen prácticamente en la reducción de las alternativas para la contención de la protesta a la represión oficial y para-oficial. Convencionalmente, la represión de la protesta se entiende como "el modo en que la policía maneja los actos de protesta" (Della Porta, 1999, p. 101). No obstante, en el contexto del conflicto armado colombiano esta concepción se ve desbordada. Primero, porque como se ha mencionado no son las FFAA, y dentro de ellas la policía, las únicas encargadas de reprimir, sino que debido a la doctrina contrainsurgente el ejército ha asumido funciones policiales, como la de contener las protestas, y la policía se ha militarizado, pero además hay una tendencia histórica hacia la privatización de la provisión de seguridad en general, y de la función policial en particular, que se expresa en la existencia de cuerpos para-legales que también ejercen la represión (Gutiérrez, 2014). Segundo, porque en este contexto la represión no se limita a los "actos de protesta", sino que también está orientada a prevenirlos, en la medida en que se comprenden como parte de un mismo proyecto insurgente. Francisco Gutiérrez (2014) formula un concepto de represión centrado en la amenaza o el uso de la fuerza por parte de autoridades estatales o sus simpatizantes contra sus opositores políticos. Esta concepción implica que así como existe una represión oficial, también puede existir una represión para-oficial, por medio de escuadrones de la muerte, grupos de vigilantes o, como en el caso colombiano, ejércitos paramilitares.

Así pues, el manejo de la protesta fundado en la doctrina contrainsurgente en Colombia ha estado traslapado entre lo legal y lo ilegal, cuando menos desde la emergencia de la 
subversión armada bajo el Frente Nacional. El pacto bipartidista, principalmente el reparto de los cargos estatales, terminó por deteriorar la adscripción a los partidos por la vía ideológica y por fortalecer los mecanismos clientelistas para asegurar la lealtad (Leal \& Dávila, 1991). En estas circunstancias, la reducida capacidad para distribuir la "torta burocrática" produjo una exclusión de sectores sociales emergentes que reclamaban atención estatal y participación política, a lo que se adicionó la expresión del conflicto social, ya no en la clave liberal/conservador, que durante la época de La Violencia había condensado conflictos sociales latentes, sino en términos de clase social, para conducir a un desborde de la acción política por la vía no institucional.

De acuerdo con Múnera (1998), en este momento la hegemonía política empezó a fundamentarse más en la coerción que en el consenso, lo que se articuló al clima bipolar de la Guerra Fría luego de la Revolución Cubana para fortalecer el manejo militar del conflicto y la protesta social. Esto se produjo por dos vías. De un lado, la autonomía de los militares en el manejo del orden público, presente a partir de la conocida "doctrina Lleras", que se remonta al discurso del entonces presidente Alberto Lleras ante los militares el 2 de marzo de 1958, en el que estableció una división del trabajo según la cual las FFAA no intervendrían en política y los políticos no lo harían en las políticas de seguridad. Esto configuró una autonomía de las FFAA en el mantenimiento del orden público, que se vio reforzada por la DSN. De otro lado, se recurrió en forma permanente al Estado de sitio, lo que entre otras cosas llevó al juzgamiento de civiles acusados de alterar el orden público por parte de militares. Es decir, expresiones como los movimientos sociales de la insurgencia y recibieron un tratamiento principalmente represivo y militar.

Hubo períodos de mayor represión en el denominado post-Frente Nacional, a partir del gobierno de Julio César Turbay (19781982), y su recordado Estatuto de Seguridad que amplió las atribuciones judiciales de las FFAA. Pero con el comienzo de las negociaciones de paz, en el gobierno de Betancur (1982-1986), la dinámica de represión sufrió un desborde hacia la ilegalidad. En efecto, como argumenta Mauricio Romero (2003), quien ha expuesto la explicación más acertada sobre el origen del paramilitarismo, las políticas de paz y apertura política del gobierno central desencadenan una serie de reacciones de sectores adversos al desequilibrio del poder que puede potencialmente producirse a nivel regional. Las negociaciones de paz del gobierno Betancur, en especial los acuerdos de La Uribe con las FARC (22 de marzo de 1984) tenían como objetivo el tránsito de esa organización desde la lucha armada hasta la competencia electoral, para lo cual al año siguiente se formó el partido político Unión Patriótica (Dudley, 2008). Esto ocasionó el rechazo de las élites regionales, que percibieron la participación política de la insurgencia, en muchos casos exitosa, como una amenaza al statu quo en tanto que las FARC aplicaban la estrategia de "combinación de todas las formas de lucha". Ese rechazo convergió con la promoción de grupos de justicia privada por parte de narcotraficantes y terratenientes en contra de activistas progresistas y simpatizantes de la guerrilla, y la oposición de las FFAA frente a las políticas de paz. Esa dinámica, a su vez, condujo a la formación de grupos paramilitares quienes en connivencia con las autoridades se especializaron en atacar mediante amenazas, asesinatos selectivos, 
desapariciones forzadas y masacres a las poblaciones y activistas civiles de organizaciones y movimientos sociales, concebidos por ellos como "para-subversivos" (Valencia \& Celis, 2012).

Las prácticas oficiales y para-oficiales de la represión no amainaron a pesar de los acuerdos de paz y las desmovilizaciones de grupos guerrilleros realizadas a principios de los años noventa y del nuevo pacto constitucional de 1991 que, entre otras cosas, limitó el uso de los estados de excepción porque los principales grupos guerrilleros -las FARC y el Ejército de Liberación Nacional (ELN)- se negaron a dejar las armas. Así, ni el contexto internacional post Guerra Fría, ni los cambios institucionales en el país consiguieron terminar con el arraigo de las políticas y discursos contrainsurgentes. Por el contrario, el país pareció sumergirse con más ahínco en la bipolaridad de la Guerra Fría. Tras el fracaso de las negociaciones de paz en Caracas y Tlaxcala con la Coordinadora Guerrillera Simón Bolívar (CGSB), el gobierno de Gaviria (1990-1994) optó por la intensificación de la confrontación. Mediante la declaratoria del estado de conmoción interior expidió medidas tendientes a la financiación de la guerra, como los "bonos de guerra" para el sector privado, y declaró una "guerra integral" a la guerrilla (Pardo, 1996). Lo que vendría después sería un escalamiento sostenido de la violencia procedente del conflicto armado que entre otras cosas llevaría a la consolidación del paramilitarismo, primero en el marco de las Autodefensas Unidas de Córdoba y Urabá (ACCU) en 1994 y, más tarde, con las Autodefensas Unidas de Colombia (AUC).

Ahora bien, la represión para-oficial no sólo se ejerce en el marco del conflicto armado. Por otra parte, pero con distintas formas de articulación, existen complejos fenómenos de represión que se entrecruzan con la "guerra sucia" agenciada por el paramilitarismo, que hasta cierto punto constituyen repertorios de violencia complementarios, entre los que puede destacarse la "limpieza social", las amenazas y asesinatos de ciertos sujetos que se perciben como amenazas para el orden social establecido. Se trata de:

un fenómeno fundamentalmente urbano y dirigido contra un espectro específico de personas que tienen en común el pertenecer a sectores sociales marginados y asumir comportamientos rechazados y considerados como peligrosos por los agresores. En efecto, sus víctimas han sido en lo fundamental delincuentes, recicladores, jóvenes y niños de la calle, homosexuales, prostitutas e indigentes, todos ellos caracterizados por sus victimarios como "elementos no aptos para convivir en sociedad. (Rojas, 1996, p. 17)

Algunas veces, la "limpieza social" es agenciada por ciudadanos que se organizan en "escuadrones de la muerte" para garantizar su seguridad; otras veces es orquestada por la "mano negra" de las fuerzas de seguridad, como cuando a esta práctica se asociaban los temibles Departamento Administrativo de Seguridad (DAS) y el F2 de la policía. Este fenómeno, que apareció a fines de los años setenta en la ciudad de Pereira, se caracterizó por contener un fuerte carácter aleccionador. Los panfletos amenazantes y su circulación tienen un efecto performativo, al crear esa identidad negativa en personas, lugares, oficios, formas de ser y de pensar, que no corresponden con el ideal de sociedad que inspira la "limpieza social" y que por tal razón se convierten en sus blancos. Hace algunas décadas, en los inicios de esa práctica, cuando una persona acusada de delincuente era asesinada, po- 
dría aparecer con algún letrero indicando "me mataron por ladrón" o algo por el estilo; un mensaje que no iba dirigido solamente a los "delincuentes", sino a toda la sociedad. En otras palabras, la limpieza social ejemplifica, en el fondo, lo que a cualquiera que ose contrariar esa visión particular del orden puede pasarle. Tiene también un marcado sesgo político clasista, y es eso lo que explica que se haya ensañado en contra de líderes populares y defensores de derechos humanos. Las horrorosas masacres para aleccionar poblaciones que han tenido lugar en este país tienen en la "limpieza social" de las ciudades un fenómeno análogo, de menor escala pero cuya lógica y fines son los mismos: aleccionar potenciales sujetos ingobernables. Mejor dicho, nunca han estado claros los límites entre la "limpieza social" y la "guerra sucia", pues ambas han estado orientadas a acabar con el tejido social y las formas organizativas de los movimientos sociales.

La represión para-oficial parece ser una constante en la historia colombiana, y debe tenerse muy en cuenta para que, cuando se empiece a hablar de la participación política de la insurgencia, se tomen las medidas necesarias a fin de terminar de una vez por todas con la guerra sucia. Más aún cuando, ad portas de un post-conflicto, no ha podido terminarse con el fenómeno del paramilitarismo, que ahora como antes combina distintos repertorios para ejercer la represión. Así lo confirma la operación de lo que ha dado en denominarse "bandas criminales" (Bacrim), que proceden de mandos medios del antiguo paramilitarismo que no se desmovilizaron durante las negociaciones con el gobierno Uribe o que retornaron a sus actividades y ahora combinan el crimen organizado con su acción contrainsurgente. La operación de "Los Urabeños", "Los Rastro- jos" o el "Ejército antirestitución" en distintas regiones, confirma que la "desmovilización" del paramilitarismo, que inició hace una década, fracasó (Pardo, 2007). No se acabó con las estructuras militares y no sabemos hasta qué punto se conservan sus oscuras estructuras de financiación y sus influencias en sectores del Estado.

\section{Las instituciones: la policía y la ley}

Dispositivos institucionales, que han estado marcados por las políticas contrainsurgentes, la militarización y privatización de la seguridad, deberían repensarse en un hipotético post-conflicto, porque hacen aún más precario el derecho a la protesta en Colombia. El cuerpo policial especializado en el manejo de la protesta, el Escuadrón Móvil Antidisturbios de la Policía Nacional (Esmad), se caracteriza por una concepción de la protesta sesgada por la ideología contrainsurgente y un alto nivel de militarización. En el mismo sentido, la legislación sobre la protesta la restringe hasta tal punto de llegar a prohibirla tácitamente. Ambos problemas conducen a la represión y criminalización persistente de la protesta social.

El Esmad ha sido sistemáticamente cuestionado por el ejercicio desproporcionado de la fuerza. Este cuerpo fue creado, en parte, con los recursos del Plan Colombia, en 1999, y desde entonces se han presentado abundantes críticas y denuncias por su proceder. En efecto, en muchas de las protestas en las que el Esmad ha actuado, en confusas situaciones han sido asesinadas varias personas (Corporación Jurídica Libertad, 2011). Se presume que algunas de estas muertes fueron ocasionadas como consecuencia del uso de armas no convencionales o no autorizadas. Es el caso del estudiante de la Universidad 
Distrital, Oscar Salas, quien murió porque durante una protesta en la Universidad Nacional, el 8 de marzo de 2006, una canica le perforó el cráneo y se alojó en su cerebro (Gómez, 2011). Muchas veces se presenta un uso inadecuado de las armas, como durante el paro de transportadores de marzo de 2010 en Bogotá, cuando un efectivo del Esmad disparó un gas lacrimógeno a quemarropa en el pecho al joven Édgar Bautista, hechos que fueron transmitidos por el canal City TV ( $\mathrm{Pa}$ checo, 2010).

Incluso varios casos de extrema gravedad han sido denunciados ante la Corte Interamericana de Derechos Humanos. Por ejemplo, el caso del niño Nicolás Neira, asesinado a golpes el 1 de mayo de 2005 mientras participaba en una manifestación en la Plaza de Bolívar en Bogotá (Orozco, 2010); el del estudiante de la Universidad del Valle, Jhonny Silva Aranguren, asesinado el 22 de septiembre de 2005, con un disparo en la nuca durante una protesta estudiantil, cuando agentes del Esmad ingresaron al campus de la Universidad (El Espectador, 2009); o el del indígena Belisario Camayo, asesinado en enfrentamientos con el Esmad, con tiros de fusil, el 10 de noviembre de 2005, cuando participaba en una ocupación pacífica de tierra en la hacienda "El Hapio", en el Valle del Cauca (Equipo Nizkor, 2005).

Por esas razones, se ha llegado a plantear la reforma e incluso el desmonte de dicho cuerpo policial. Sin embargo, por el contrario, el Esmad ha crecido de forma significativa desde su creación. Así, si al principio contaba con 200 patrulleros, 8 suboficiales y 9 oficiales, a 2011 había llegado a tener 1950 efectivos con presencia en 12 ciudades del país (Gómez, 2011). Incluso el Ministerio de Defensa ha planteado la necesidad de duplicar su número (El Espectador, 2013). Claramen- te, este tipo de propuestas no han tomado en cuenta los problemas antes mencionados, ni mucho menos realizado un diagnóstico de sus causas.

Recientemente, el caso que más atrajo la atención sobre los problemas del Esmad fue el paro agrario, en agosto de 2013. La contrainsurgencia y la militarización de la función policial explican en buena parte los desmanes que se presentaron por parte de la Policía en regiones como Boyacá, más propios de la campaña militar que de un cuerpo civil policial. Desde los primeros días de la manifestación empezaron a circular denuncias en las redes sociales virtuales acerca del abuso de la fuerza por parte del Esmad (Semana, 2013). Los hechos llevaron, en un hecho inédito en la historia reciente, a que el Presidente Juan Manuel Santos se dirigiera al país para presentar disculpas por los desmanes. Avanzada la protesta, se conocieron denuncias puntuales por parte de organismos defensores de derechos humanos, que daban cuenta no sólo del uso excesivo de la fuerza, sino de crímenes por parte del cuerpo policial en contra de los derechos humanos y el derecho internacional humanitario, como el empleo de armas de fuego, armas blancas no autorizadas y armas no convencionales, el uso de gases lacrimógenos en lugares cerrados, la destrucción y el hurto de bienes de los campesinos, el empleo de ambulancias para transporte de los policiales, las torturas y los abusos sexuales contra hombres y mujeres, entre otros (Equipo Nizkor, 2013).

En el fondo, el sesgo represivo del Esmad reproduce tanto la perspectiva contrainsurgente como el problema de la militarización de la función policial, las cuales lejos de atenuarse se profundizaron con la implementación de la política de seguridad democrática (Casas, 2005). La función de los agentes del Esmad 
está orientada a la "atención, manejo y control de multitudes" (Policía Nacional de Colombia, 2011). Para ello, reciben permanentemente distintos tipos de entrenamiento, formación en derechos humanos y "psicología de masas". Esto último permite inferir de entrada que existe un sesgo muy complicado en un contexto como el colombiano: se confunde la protesta con disturbios, motines y otras conductas de "masas" o "multitudes". Esta confusión parece actualizar los sesgos del enfoque de la "psicología de las masas", desarrollado en Europa en la segunda mitad del siglo XIX por teóricos positivistas como Gustave Le Bon (1952), que veían los comportamientos colectivos como expresión de una enfermedad del cuerpo social que sólo podría explicarse por la irracionalidad, el contagio, la manipulación y la sugestión de la que son presas los individuos cuando hacen parte de una masa, quienes debían tener un tratamiento con énfasis en el ejercicio de la fuerza.

Así pues, este cuerpo policial encuentra su base en la confusión entre protesta y disturbio, que como se mencionó es un prejuicio que, cuando no utilizado estratégicamente para criminalizar la protesta, es ampliamente difundido en el sentido común y en los medios masivos de comunicación, por el efecto de la propaganda contrainsurgente. En el fondo, ello evidencia la permanencia de una mentalidad propia de la Guerra Fría que ha militarizado la función policial y que lleva a ver cualquier protesta como un acto que atenta contra el orden o se asocia a la insurgencia armada y, por consiguiente, a identificar a quien protesta con un enemigo al que se debe doblegar y no como un ciudadano al que se debe proteger en tanto ejerce un derecho. En las actuaciones de una policía militarizada tiende a primar el criterio de garantizar la seguridad del Estado, frente a la amenaza insurgente, que la seguridad tanto de los ciudadanos que protestan como de aquellos que se ven afectados por sus acciones.

En consecuencia, un eventual post-conflicto plantea la necesidad de pensar políticas integrales del manejo a la protesta que partan de la primacía de la seguridad ciudadana y vayan más allá de la represión policial, e incluso plantear la posibilidad del desmonte o la reforma del cuerpo policial especializado, el Esmad, y su reemplazo por un cuerpo policial idóneo para garantizar los derechos que se pueden ver vulnerados a consecuencia de la protesta. Por ejemplo, durante las marchas estudiantiles de 2011, se hicieron acuerdos de convivencia con la Alcaldía de Bogotá para limitar la presencia del Esmad, y no se presentaron actos violentos como los registrados durante la última semana del paro agrario en agosto de 2013.

Ahora bien, las acciones del Esmad tienen un fundamento legal que restringe las posibilidades de la protesta. En efecto, la sinonimia entre protesta y disturbio o, más recientemente, "vandalismo", tiene una base legal que no deja de generar confusiones. La Ley 1453 de 2011, o de "seguridad ciudadana", restringe hasta penalizar el derecho de protesta, pues en su artículo 353A castiga con años de cárcel los bloqueos "por medios ilícitos", lo cual deja un amplio margen de interpretación si se tiene en cuenta que toda protesta implica generar algún tipo de malestar a la comunidad con el fin de llamar la atención sobre un problema socialmente relevante o tramitar una demanda desatendida. Por tanto, aunque la policía sólo puede usar la fuerza cuando es estrictamente necesario para proteger la vida de modo diferencial y progresivo, la legislación vigente obliga a los agentes a emplear la fuerza. 


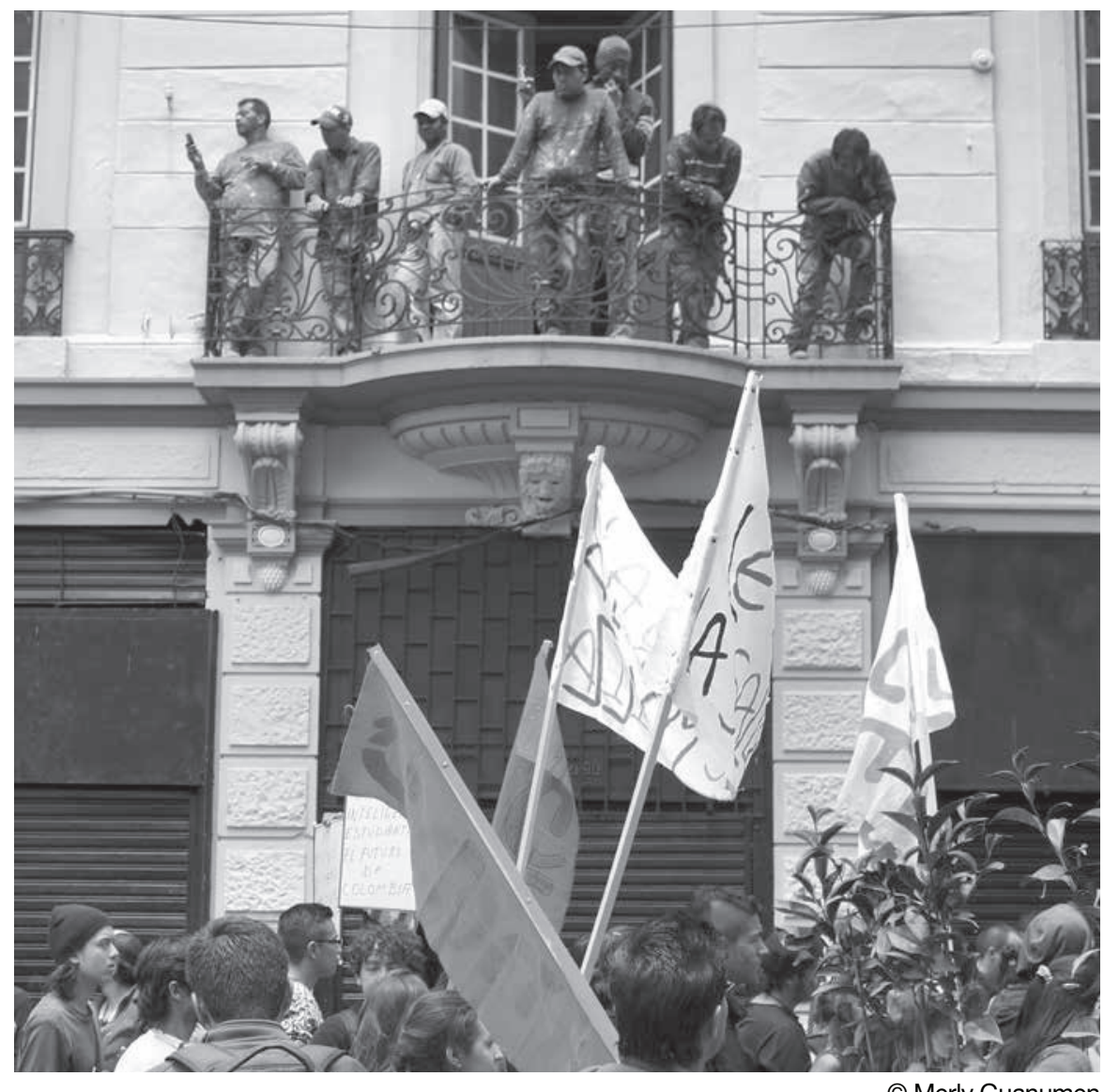

(C) Merly Guanumen

En cualquier Estado democrático el derecho a la protesta supone que los ciudadanos pueden manifestar su descontento frente a determinadas políticas de las autoridades, siempre que ello no implique el uso de la violencia, tal como está consagrado en el Artículo 37 de nuestra Constitución Política. No obstante, este no es el caso de Colombia, donde la protesta está penalizada por la mencionada Ley. El artículo 353A "Obstrucción a vías públicas que afecten el orden público", declarado exequible por la Corte Constitucional (Sentencia C-742 de 2012), afirma:

El que por medios ilícitos incite, dirija, constriña o proporcione los medios para obstaculizar de manera temporal o permanente, selectiva o general, las vías o la infraestructura de transporte de tal manera que atente contra la vida huma- na, la salud pública, la seguridad alimentaria, el medio ambiente o el derecho al trabajo, incurrirá en prisión de veinticuatro (24) a cuarenta y ocho meses (48) y multa de trece (13) a setenta y cinco (75) salarios mínimos legales mensuales vigentes, y pérdida de inhabilidad de derechos y funciones públicas por el mismo término de la pena de prisión. Parágrafo. Se excluyen del presente artículo las movilizaciones realizadas con permiso de la autoridad competente en el marco del artículo 37 de la Constitución Política.

El parágrafo nos informa que no serán penalizadas las protestas autorizadas, lo cual supone que es necesario que los ciudadanos pidan permiso a la autoridad para manifestar su descontento con ella misma, lo que indica que el ejercicio de tal derecho depende en 
última instancia de las autoridades. Por otra parte, la Corte resaltó que sólo se penalizarían los bloqueos cuando utilizaran medios "ilícitos", es decir, ilegales. A priori, entonces, el bloqueo de una vía no necesariamente vulnera la ley. Empero, es prácticamente imposible discernir in situ cuáles serían medios "ilícitos" para bloquear y cuáles no. En consecuencia, la ley está penalizando aquello que Tarrow (1997) caracteriza como uno de los elementos esenciales de la protesta: el "desafío colectivo". Para él, la violencia no es un rasgo distintivo de la protesta, no toda protesta tiene que ser violenta. Sin embargo, por más pacífica que sea, toda protesta debe plantear un "desafío colectivo", esto es, debe introducir incertidumbre en las actividades cotidianas de los otros; sin esa incertidumbre, sin esa interrupción de la regularidad y de la cotidianidad, nadie sabría que existe una protesta, que existe descontento o que alguien está inconforme.

Un escenario de post-conflicto plantea el reto de revisar las políticas de contención de la protesta social, más allá de la criminalización y de la represión. Esto pasa por reformas jurídicas que inserten un concepto más atento a las dinámicas concretas de la protesta social, pero no se agota ahí. Se necesita un cuerpo policial con orientación civil, es decir desmilitarizado y guiado por una concepción de seguridad ciudadana más que de seguridad nacional, capaz de ver en los manifestantes a ciudadanos en ejercicio de sus derechos, más que enemigos o insurgentes. Se requieren políticas comprensivas de manejo de la protesta que actúen sobre la cultura política "antiprotesta" producto del predominio de la visión contrainsurgente.

Como lo muestran los casos centroamericanos, en el post-conflicto tanto los problemas sociales como la criminalidad y la violencia tienden a incrementarse (Rettberg et. al., 2002). Con frecuencia, de ello se ha inferido la necesidad de una política de seguridad basada en la coerción, sobre todo si se tiene en cuenta que el post-conflicto colombiano será necesariamente parcial, en tanto persistirán distintas formas de violencia organizada (Llorente, Ortíz \& Urrutia, 2008). Sin embargo, esos casos también muestran que los conflictos sociales y la violencia no sólo se explican por los reductos de organizaciones especializadas en el ejercicio de la violencia con fines políticos o criminales y por los aprendizajes que esta actividad genera en el conflicto armado, sino, sobre todo, porque los acuerdos de paz no se traducen de forma inmediata en la solución a los problemas socioeconómicos, políticos e institucionales que estuvieron en el origen de la guerra (Wielandt, 2005; Cardenal, 2008). Por consiguiente, el post-conflicto no sólo requiere políticas represivas sino también políticas que contribuyan a resolver los problemas que dieron pie a la guerra (Benavides, 2010). Como se ha visto en el caso colombiano, y sin llegar a reducir la complejidad del conflicto, uno de esos problemas está referido a la vulneración de los derechos políticos de algunos sectores sociales. Parte de la solución es la garantía plena del derecho a la protesta social.

\section{Corolario}

Un eventual escenario de post-conflicto plantea, entre otras cosas, la necesidad de garantizar el derecho a la participación política. Este no se agota en el acceso al sistema político institucional, sino que comprende otras formas de acción política, como la protesta social, que ha tenido una revitalización en los últimos años. 
El conflicto armado afecta de maneras muy diferenciadas las dinámicas de la protesta social y de la acción colectiva en general. No es posible establecer relaciones lineales entre las variables comprendidas por ambos fenómenos. Sin embargo, es claro que la guerra impone unos límites objetivos a las posibilidades de llevar a cabo protestas de amplio alcance temporal y espacial, al reducir las oportunidades de organización, afectar el tejido social, disminuir las oportunidades políticas y limitar la política a la relación entre amigos y enemigos a muerte. Esto puede corroborarse si se tiene en cuenta que aunque el país comparte muchas de las variables que en otros casos de América Latina contribuyen a explicar los recientes ciclos de protesta, aquí no se han presentado.

El legado de la Guerra Fría, que se mantiene en la sociedad colombiana gracias a la prolongación del conflicto armado, ha generado un ambiente poco propicio para aceptar la protesta social como el ejercicio de un derecho. Por el contrario, tanto la DSN como las políticas de contrainsurgencia han fomentado en distintos sectores y niveles de la sociedad una orientación contrainsurgente que criminaliza y reprime la protesta, al concebirla como una parte del proyecto de la insurgencia armada, promoviendo en consecuencia un tratamiento fundamentalmente militar de los conflictos sociales.

Eso se traduce en la represión como el modo predominante de manejar la protesta social. Una represión que por las características del conflicto armado es desarrollada por vías legales e ilegales, oficiales y para-oficiales, debido tanto a la militarización como a la privatización de la función policial, desde los ejércitos paramilitares hasta la "limpieza social". En fin, el legado de la Guerra Fría se proyecta sobre el cuerpo de policía especializado en el manejo de la protesta, puesto que tiene una orientación militarista y contrainsurgente fundada en un concepto de seguridad nacional más que en la seguridad ciudadana, y en la legislación que regula esa actividad, que se caracteriza por penalizar sus acciones básicas y prácticamente prohibirla.

En consecuencia, pensar la protesta social en el post-conflicto equivale a discutir el contexto en el que esta se produce. El post-conflicto plantea como su principal desafío salir de la lógica de la Guerra Fría que ha constituido esa especie de "sociedad contrainsurgente" que previamente se examinó. A partir de allí es necesario promover políticas que ataquen los sesgos contrarios a la protesta que persisten en la sociedad y en la cultura política, así como en las instituciones públicas: desprivatizar la función de policía, es decir, acabar con el fenómeno del paramilitarismo en todas sus variantes, y desmilitarizar la policía y las políticas de seguridad.

En particular, es necesaria una reforma del cuerpo de policía especializado en el manejo de la protesta que pase por su desmilitarización y por la asunción del concepto de seguridad ciudadana como reemplazo del énfasis en la seguridad nacional que aún predomina, si no en su doctrina por lo menos sí en sus acciones. La función de contención de la protesta debe estar orientada a prevenir el conflicto y la violencia, garantizar y proteger los derechos de los ciudadanos, tanto de los que protestan como los que se ven afectados por este tipo de acciones. Del mismo modo, es necesario generar un marco legal que atienda a las características concretas de las acciones de protesta y coadyuve a ver en ella el ejercicio legítimo de un derecho, más que un crimen potencial que hay que penalizar.

Todo lo anterior pasa por comprender que la protesta no necesariamente es desorden e ingobernabilidad y que, por el contrario, 
es necesaria para la consolidación de la democracia, porque entre otras cosas permite la expresión de demandas y actores cuyos intereses no logran ser articulados por los partidos políticos, y mejora la legitimidad y la eficacia del sistema político.

\section{Referencias bibliográficas}

- Acosta, A. (2005). Ecuador: ecos de la rebelión de los forajidos. Nueva Sociedad, (198), 42-54.

- Archila, M. (2002). Balance de 25 años de luchas en Colombia. Conclusión. En M, Archila. 25 años de luchas sociales en Colombia 1975-2000 (pp. 241-253). Bogotá, Colombia: Cinep.

- Archila, M. (2003). Idas y venidas, vueltas y revueltas. Bogotá, Colombia: Cinep-Icanh.

- Archila, M; Angulo, A; Delgado, Á; García, M \& Parra, L. (2012). Violencia contra el sindicalismo 1984-2010. Bogotá, Colombia: Cinep.

- Benavides, E. (2010). Los desafíos de la prevención de la criminalidad en contexto de postconflicto: la experiencia de Guatemala. Serie Nuevas Voces, No 1, agosto, Consorcio Global para la Transformación de la Seguridad.

- Cabezas, M. (2007) Caracterización del "ciclo rebelde» 2000-2005. En Iglesias, P \& Espasandín, J. (Coords.). Bolivia en movimiento. Acción colectiva y poder político (pp. 189-219). España: El Viejo Topo.

- Cardenal, A. (2008) ¿Son las guerras civiles responsables del crimen en Centroamérica? Revista CIDOB d'Afers Internacionals, (81), 67-90.

- Cárdenas, M. (2003). La construcción del post-conflicto en Colombia. Bogotá, Colombia: FESCOL-CEREC-CESO-UNIJUS.

- Casas, P. (2005). Reformas y contrarreformas en Policía colombiana. En WVA. Seguridad urbana y policía en Colombia (pp. 1-80). Bogotá, Colombia: Fundación Seguridad y Democracia.

- Corporación Jurídica Libertad. (2011). Esmad: ¿Dónde queda el derecho a disentir? Recuperado de http://goo.gl/OzhhE1

- Cruz, E. (2012a). La mane y el paro nacional universitario de 2011 en Colombia. Ciencia Política, (14), 140 - 193.

- Cruz, E. (2012b). Movimientos sociales y democracia: una reflexión a propósito del caso colombiano. Diálogos De Saberes, (37), 115 - 128.

- Cruz, E. (2013).Todos somos hijos del café: Sociología política del paro nacional cafetero. Entramado, 9(2), 138 - 158

- Cruz, E. (2014). Dignidad en movimiento. El ascenso de la movilización social en Colombia. Confluenze. Revista di Studi lberoamericani Università di Bologna, 6(25), $241-275$.

- Della Porta, D. (1999). Movimientos sociales y Estado: algunas ideas en torno a la represión policial de la protesta. En McAdam, D; McCarthy, J \& Zald, M (eds.). Movimientos sociales: perspectivas comparadas. Oportunidades políticas, estructuras de movilización y marcos interpretativos culturales (pp. 100-142). Madrid, España: Itsmo.

- Dudley, S. (2008). Armas y urnas. Bogotá, Colombia: Planeta.

- Caso Jhonny Silva, a la CIDH. (2009, 17 de junio). El Espectador. Recuperado de http://goo.gl/tgHLLQ

- "El ESMAD no se va a acabar. Se duplicará: Mindefensa". (2013, 19 de septiembre). El Espectador, Recuperado de http://goo.gl/ZKthM7

- Equipo Nizkor, (2005). Asesinado indígena Belisario Camayo Guetoto defensor de los derechos al territorio. Recuperado de http://goo.gl/fayq2h

- Equipo Nizkor, (2013). Agresiones de la Fuerza Pública contra la población civil en el marco del paro agrario y popular. Recuperado de http://goo. $\mathrm{gl} / \mathrm{XqeYWy}$

- Franco, V. (2002). El mercenarismo corporativo y la sociedad contrainsurgente. Estudios políticos, (21), 54-82.

- García, M. (2006). Movimiento por la paz en Colombia 1978-2003. Bogotá, Colombia: Cinep.

- Godás, X. (2007). Política del disenso. Sociología de los movimientos sociales. Barcelona, España: Icaria.

- Gómez, A. (2011). El escuadrón de la muerte. Recuperado de http://goo.gl/jghol9

- Gutiérrez, O. (2004). La oposición regional a las negociaciones con el ELN. Análisis político, (52), 34-50.

- Gutiérrez, F. (2007). ¿Lo que el viento se llevó?. Bogotá, Colombia: Norma-Universidad Nacional de Colombia.

- Gutiérrez, F. (2014). El orangután con sacoleva. Cien años de democracia y represión en Colombia (1910-2010). Bogotá, Colombia: DebateUniversidad Nacional de Colombia.

- Hirts, M. (2003). Seguridad regional en las Américas. En Grabendorff, W (ed.). La seguridad regional en las Américas (pp. 25-79). Bogotá, Colombia: FESCOL-CEREC

- Kruse, T. (2005). La «querra del agua» en Cochabamba, Bolivia: terrenos complejos, convergencias nuevas. En De La Garza, E. (comp.). Sindicatos y nuevos movimientos sociales en América Latina (pp. 121-161). Buenos Aires, Argentina: Clacso.

- Le Bon, G. (1952). Psicología de las multitudes. Buenos Aires, Argentina: Albatros.

- Leal, F. (2006). La inseguridad de la seguridad. Bogotá, Colombia: Planeta.

- Leal, F \& Dávila Ladrón de Guevara, A. (1991). Clientelismo. El sistema político y su expresión regional. Bogotá, Colombia: Tercer MundoUniversidad Nacional de Colombia.

- Llorente, M. V., Ortiz, R., \& Urrutia, N. (2008). Policía Nacional: Una fuerza para la consolidación, Propuestas(3). Bogotá, Colombia: Fundación deas para la Paz.

- López de la Roche, F. (2014). Las ficciones del poder. Patriotismo, medios de comunicación y reorientación afectiva de los colombianos bajo Uribe Vélez (2002-2010). Bogotá, Colombia: Debate-Universidad Nacional de Colombia.

- Lucas, K \& Cucurella, L. (2001). "Nada solo para los indios". El levantamiento indígena del 2001: Análisis, crónicas y documentos. Quito, Ecuador: Abya Yala.

- Melucci, A. (1999). Acción colectiva, vida cotidiana y democracia. México: El Colegio de México.

- Múnera, L. (1998). Rupturas y continuidades. Bogotá, Colombia: Universidad Nacional de Colombia-CEREC.

- Novoa, E. (2009). Trayectorias geopolíticas en Colombia. Bogotá, Colombia: Universidad Nacional de Colombia.

- Orozco, Y. (2010). El escuadrón móvil antidisturbios y la protección de los derechos humanos. Trabajo de grado para obtener el título de Magister en Derecho Público Militar. Universidad Militar Nueva Granada. Recuperado de http://goo.gl/M7EUAH

- Pacheco, D. (2010). Óscar Salas y las víctimas del Esmad. Recuperado de http://goo.gl/mBPqyV

- Pardo, R. (1996). De primera mano. Bogotá, Colombia: Planeta.

- Pardo, R. (2007). Fin del paramilitarismo. ¿Es posible su desmonte? Bogotá, Colombia: Ediciones B Colombia

- Pécaut, D. (2001). Guerra contra la sociedad. Bogotá, Colombia: Espasa. 
- Pécaut, D. (2003). Midiendo fuerzas. Bogotá, Colombia: Planeta.

- Peñaranda, R. (2006). Resistencia civil y tradiciones de resistencia en el suroccidente colombiano. En Gutiérrez, F; Sánchez, G \& Wills, M. Nuestra Guerra sin nombre (pp.543-569). Bogotá, Colombia: Norma-Universidad Nacional de Colombia.

- Peñaranda, R. (ed.) (2011). Contra viento y marea. Acciones colectivas de alto riesgo en las zonas rurales colombianas 1985-2010. Medellín Colombia: La Carreta-Universidad Nacional de Colombia.

- Policía Nacional de Colombia. (2011). Manual para el servicio de policía en la atención, manejo y control de multitudes. Recuperado de http://goo. $\mathrm{gl} / \mathrm{Ft} 6 \mathrm{nLH}$

- Ramírez, F. (2000). El 21 de enero del 2000. OSAL, (1), 17-21.

- Rettberg, A. (coord.). (2002). Preparar el futuro: conflicto y postconflicto en Colombia. Bogotá, Colombia: Uniandes-FIP.

- Revilla, M. (1994). Gobernabilidad y movimientos sociales. Una relación difícil. América Latina Hoy, (8), 21-25.

- Rivas, A. (1998). El análisis de los marcos: una metodología para el estudio de los movimientos sociales. En Ibarra, P \& Tejerina, B. (Eds.). Los movimientos sociales. Transformaciones políticas y cambio cultural (pp. 181-215). Madrid, España: Trotta.

- Rodríguez, C; Barret, P. \& Chávez, D. (eds.). (2005). La nueva izquierda en América Latina. Sus orígenes y trayectoria futura. Bogotá, Colombia: Norma.

- Rojas, C. (1996). La Violencia llamada limpieza social. Bogotá, Colombia: CINEP.

- Romero, M. (2003). Paramilitares y autodefensas 1982-2003. Bogotá, Colombia: IEPRI-Planeta.

- Ruch, D. (1999). El impacto de los contextos nacionales sobre la estructura de los movimientos sociales: un estudio comparado transnacional y entre movimientos. En McAdam, D; McCarthy, J \& Zald, M. Movimientos sociales: perspectivas comparadas. Oportunidades politicas, estructuras de movilización y marcos interpretativos culturales (pp. 262-287). Madrid, España: Itsmo.

- Salazar, B \& Castillo, M. (2001). La hora de los dinosaurios. Conflicto y depredación en Colombia. Bogotá, Colombia: CIDSE-CEREC.

- Sánchez, G. (1991). Guerra y política en la sociedad colombiana. Bogotá, Colombia: El Áncora.

- La golpiza del Esmad a un campesino. (2013, 23 de agosto). Semana, Recuperado de http://goo.gl/MIAay4

- Silva, D. (2011). Asociaciones campesinas en resistencia civil. Construcción de paz y desarrollo en el Magdalena Medio. Bogotá, Colombia: Uniminuto-CEHIIS.

- Tarrow, S. (1997). El poder en movimiento. Los movimientos sociales, la acción colectiva y la política. Madrid, España: Alianza.

- Tilly, Ch. \& Wood, E. (2010). Los movimientos sociales 1768-2008. Desde sus orígenes a Facebook. Barcelona, España: Crítica.

- Torres, E. (1993). América Latina. Gobernabilidad y democracia en sociedades en crisis. Nueva Sociedad, (128), 88-101.

- Uprimny, R \& Vargas, A. (1990). La palabra y la sangre: Violencia, legalidad y guerra sucia en Colombia. En Palacio, G. (Compilador). La irrupción del paraestado. Ensayos sobre la crisis colombiana (pp. 105-166). Bogotá, Colombia: ILSA-CEREC.

- Uribe De Hincapié, M. (2004). Emancipación social en un contexto de guerra prolongada. El caso de la Comunidad de Paz de San José de Apartadó. En Santos, B \& García, M. Emancipación social y violencia en Colombia (pp. 75-117). Bogotá, Colombia: Norma.

- Valencia, L\& Celis, J. (2012). Sindicalismo asesinado. Bogotá, Colombia: Debate.

- Wielandt, G. (2005). Hacia la construcción de lecciones del postconflicto en América Latina y el Caribe. Una mirada a la violencia juvenil en Centroamérica. Santiago de Chile: Cepal.

- Wills, L \& Benito, Ch. (2012). De Uribe a Santos: cambios y continuidades de la política colombiana en 2011. Revista de Ciencia Política, 32(1), 87-107. 